〈Research Paper〉

\title{
Synthesis and Optical Properties of Novel Chemosensor Based on Rhodamine 6G
}

\author{
Hyungjoo Kim and Young-A Son ${ }^{\dagger}$ \\ Department of Advanced Organic Materials and Textile System Engineering, \\ Chungnam National University, Daejeon, Korea
}

(Received: November 3, 2012 / Revised: December 12, 2012 / Accepted: December 13, 2012)

\begin{abstract}
The opto-functional materials have been developed as a promising research topic toward the end uses for optical materials and applications. The attractive area in this part was the design of sensor molecules for detecting harmful environmental factors. These harmful factors impart undesired effects on wide range of chemical and biological phenomenon. In this context, many researchers have studied luminescence chemosensor materials. These sensor molecules showed optical signals such as color or fluorescence change by detecting harmful environmental factors. In this study, the novel fluorescence chemosensor 1 has been designed and synthesized through reaction of rhodamine $6 \mathrm{~g}$ hydrazide and 2-hydroxy-1-naphthaldehyde. The chemosensor 1 had been analyzed by UV-Vis and fluorescence spectrophotometer. We found that this chemosensor 1 has 'off-on' and dual type sensing properties toward $\mathrm{Cu}^{2+}$ and $\mathrm{Mg}^{2+}$.
\end{abstract}

Keywords: Rhodamine 6G, chemosensor, absorption, fluorescence, metal ions, HOMO/LUMO

\section{Introduction}

The copper affects in various environmental pollutions and biological processes due to its property of cycle between multiple oxidation states ${ }^{1)}$. The magnesium also affects in various biological processes and environmental ${ }^{2}$. Hence, sensing and monitoring for these copper and magnesium metals are important to human and environmental. Many researchers have been investigated for various kinds ofchemosensor based on different chromophores and phosphors such as anthraquinone, coumarin, rhodamine ${ }^{3)}$. Chemosensors based on these materials plays a role as useful materials for detection of metal ions due to their selectivity and sensitivity and real-time monitoring ${ }^{4-6}$. The rhodamine dye material has been used widely to investigate chemosensors due to its excellent fluorescence property ${ }^{7}$.

As is well-known, rhodamine derivatives provides an proper mode for the frame of new 'off-on' type fluorescence sensor based on spiro-lactam (non-fluorescent) to ring-opened amide (fluorescent) process utilized for the detection of metal ions ${ }^{8-10)}$.

In this study, we have designed and synthesized a

${ }^{\dagger}$ Corresponding author: Young-A Son (yason@cnu.ac.kr)

Tel.: +82-42-821-6620 Fax.: +82-42-823-3736

(C) 2012 KSDF 1229-0033/2012-12/233-238 novel chemosensor based on rhodamine $6 \mathrm{G}$ derivatives. This novel chemosensor detected $\mathrm{Cu}^{2+}$ and $\mathrm{Mg}^{2+}$ ions, which showed yellow and green fluorescence emission visible to naked-eye with compared to other investigated metal ions. Its properties of $\mathrm{Cu}^{2+}$ and $\mathrm{Mg}^{2+}$ detection were investigated and analyzed in fine points. Structural analysis of this novel dye sensor was identified by ${ }^{1} \mathrm{H}-\mathrm{NMR}$, Mass and Elemental analysis. Optical sensing properties were investigated using UV-Vis absorption and fluorescence emission measurement.

The metal complex formation was measured by Job's plot method. Finally, electron distribution and energy level calculation such as HOMO and LUMO was computationally simulated using DMol3 program of Materials Studio 4.3 package.

\section{Experimental}

All the reagents and solvents, used for synthesis of rhodamine $6 \mathrm{G}$ based chemosnesor 1, were purchased form Aldrich and used without further purification. Absorption and fluorescence spectra of the prepared novel chemosensor 1 were measured with and Agilent 8453 spectrophotometer and a Shimadzu RF-5301PC fluorescent spectrophotometer, respectively. 


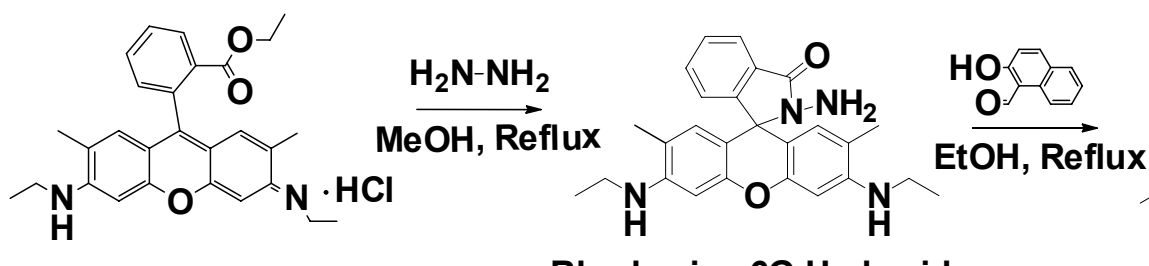

Rhodamine 6G Hydrazide

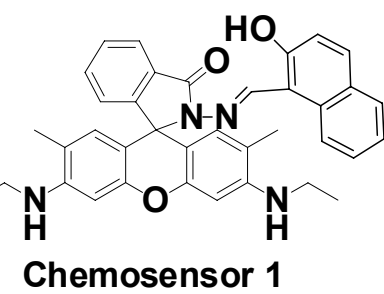

Chemosensor 1

Scheme 1. The synthetic route for chemosensor 1

${ }^{1} \mathrm{H}$ NMR spectra and elemental analyses were recorded with JNM-AL400 spectrometer operated at $400 \mathrm{MHz}$ NMR and a Carlo Elba Model 1106 analyzer, respectively. Mass spectra were recorded on a JEOL M Station [JMS-700]. HOMO/LUMO calculation and modelling simulation proceed with $\mathrm{DMol}^{3}$ of Material Studio 4.3. Electron distributions and energy potentials were also calculated with Material Studio 4.3.

Rhodamine 6G based dye compound was synthesized through 2 step reaction with rhodamine $6 \mathrm{G}$ hydrazide and 2-hydroxy-1-naphthaldehyde. The scheme was shown in Figure 1. Rhodamine 6G hydrazine is prepared according to the literature method ${ }^{11-17)}$.

Rhodamine 6G Hydrazide $(1.5 \mathrm{mmol}, 0.6437 \mathrm{~g})$ and 2-hydroxy-1-naphthaldehyde $(0.258 \mathrm{mmol}, 0.2582 \mathrm{~g})$ were dissolved in absolute EtOH.

The mixture solution was mixed and added 3 drops of acetic acid. After $8 \mathrm{~h}$, reaction mixture cooled to room temperature, yellow precipitate was filtered off, washed with EtOH. Obtained solid was recrystallized from $\mathrm{MeCN} /$ Water to give chemosensor 1 as $0.6620 \mathrm{~g}$ ( $76 \%$ yield).

${ }^{1} \mathrm{H}-\mathrm{NMR}\left(400 \mathrm{MHZ}, \mathrm{CDCl}_{3}\right): 9.78(1 \mathrm{H}, \mathrm{s}), 8.04(1 \mathrm{H}, \mathrm{t}$, $\mathrm{J}=4.4 \mathrm{~Hz}), 7.80(1 \mathrm{H}, \mathrm{d}, \mathrm{J}=8.8 \mathrm{~Hz}), 7.66(2 \mathrm{H}, \mathrm{t}, \mathrm{J}=7.2 \mathrm{~Hz})$, $7.54(2 \mathrm{H}, \mathrm{q}, \mathrm{J}=4.7 \mathrm{~Hz}), 7.44(1 \mathrm{H}, \mathrm{t}, \mathrm{J}=7.6 \mathrm{~Hz}), 7.14(1 \mathrm{H}, \mathrm{t}$, $\mathrm{J}=4.4 \mathrm{~Hz}), 7.09(1 \mathrm{H}, \mathrm{d}, \mathrm{J}=9.0 \mathrm{~Hz}), 6.47(2 \mathrm{H}, \mathrm{s}), 6.33(2 \mathrm{H}$, s), $3.50(2 \mathrm{H}, \mathrm{s}), 3.20(4 \mathrm{H}, \mathrm{q}, \mathrm{J}=6.8 \mathrm{~Hz}), 1.87(6 \mathrm{H}, \mathrm{s})$, $1.29(8 \mathrm{H}, \mathrm{t}, \mathrm{J}=7.1 \mathrm{~Hz})$. MS: $582\left(\mathrm{M}^{\dagger}\right)$.

\section{Results and Discussion}

\subsection{UV Vis and fluorescence spectra response of chemosensor 1}

We measured UV-Vis and fluorescence spectra to further investigate the selectivity of chemosesnor 1 for the result as shown Figure 1.

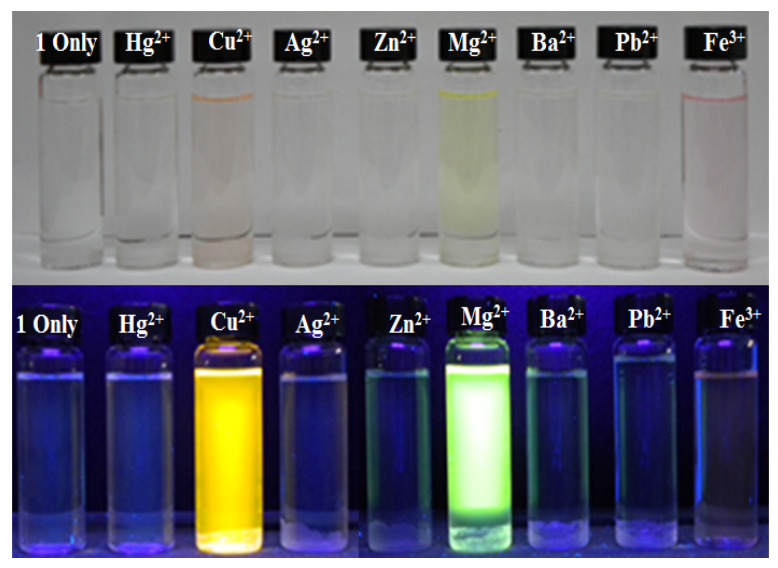

Figure 1. The picture of absorption (top) and fluorescence (bottom) change of chemosensor $1(10 \mu \mathrm{M})$ to various metal ions $(10 \mu \mathrm{M})$ in $\mathrm{MeCN}$ (Tris- $\mathrm{HCl} \mathrm{pH} 7.2$ ).

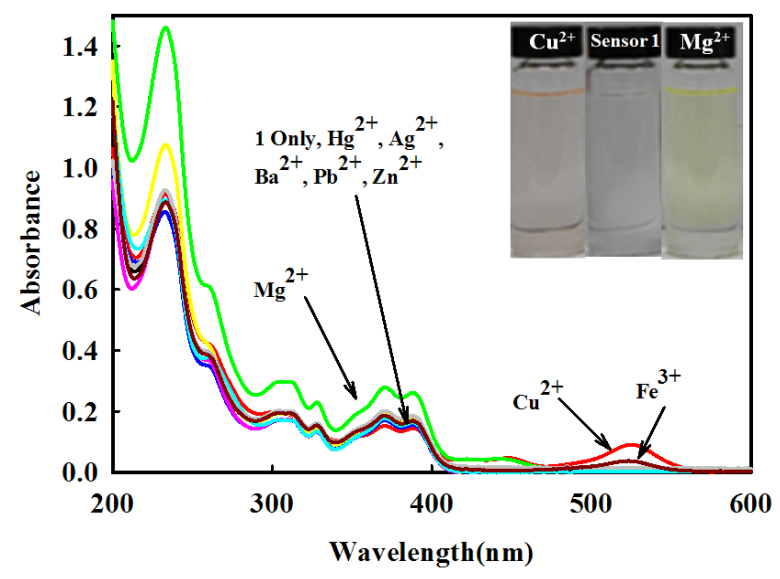

Figure 2. UV-Vis spectra of chemosensor $1(10 \mu \mathrm{M})$ upon addition of different metal ions $(10 \mu \mathrm{M})$ in $\mathrm{MeCN}$ (Tris$\mathrm{HCl} \mathrm{pH} \mathrm{7.2).} \mathrm{Inset:} \mathrm{photographs} \mathrm{of} \mathrm{color} \mathrm{change} \mathrm{for}$ sensor 1 toward $\mathrm{Cu}^{2+}$ and $\mathrm{Mg}^{2+}$ in $\mathrm{MeCN}$ (Tris- $\mathrm{HCl} \mathrm{pH}$ 7.2).

As shown in Figure 2, without metal ions, chemosensor 1 scarcely showed an absorption at 500 600nm. Upon addition of different metal ions, the chemosensor 1 with $\mathrm{Cu}^{2+}$ and $\mathrm{Fe}^{3+}$ showed absorptions. Absorption peak of $\mathrm{Cu}^{2+}$ was higher than other metal ions at $525 \mathrm{~nm}$. Absorption peak of $\mathrm{Fe}^{3+}$ also showed 
minor increase. As shown in Figure 3, without metal ions, chemosensor 1 showed non fluorescence. Upon addition of different metal ions, $\mathrm{Cu}^{2+}$ and $\mathrm{Mg}^{2+}$ only showed orange and green fluorescence at $567 \mathrm{~nm}$ and 509nm, respectively. Toward $\mathrm{Cu}^{2+}$ and $\mathrm{Mg}^{2+}$, we expect that this chemosensor 1 for absorbance and emission changes are due to spirolactam ring structure. When spirolactam ring closed, it shows colorless and nonfluorescence.

However, color and fluorescence appear when spirolactam ring open ${ }^{14)}$. Through former researches, this chemosensor 1 can be turn 'off-on' type and dual type chemosensor toward $\mathrm{Cu}^{2+}$ and $\mathrm{Mg}^{2+15)}$.

\section{$3.2 \mathrm{Cu}^{2+}$ and $\mathrm{Mg}^{2+}$ titration of chemosensor 1}

The chemosesnor 1 showed properties of detecting $\mathrm{Cu}^{2+}$ and $\mathrm{Mg}^{2+}$. In this regard, we also investigated titration of $\mathrm{Cu}^{2+}$ and $\mathrm{Mg}^{2+}$ with chemosesnor 1 .

As shown in Figure 4, upon addition of $\mathrm{Cu}^{2+}$, the absorption intensity increased at $529 \mathrm{~nm}$ peak. The absorption wavelength was red shifted from $388 \mathrm{~nm}$ to $529 \mathrm{~nm}$. Absorption intensity of the peak decreased at $388 \mathrm{~nm}$ and absorption intensity at 529nm was enhanced. This enhancement was saturated with over 6 equiv. $\mathrm{Mg}^{2+}$ titration was also shown similar results with $\mathrm{Cu}^{2+}$ titration. Upon addition of $\mathrm{Mg}^{2+}$, the absorption also increased at $448 \mathrm{~nm}$. The absorption wavelength was red-shifted from $388 \mathrm{~nm}$ to $448 \mathrm{~nm}$. The color change from colorless to yellow was shown with $60 \mathrm{~nm}$ red shift. The increase was saturated with over 16 equiv.

As shown in Figure. 5, upon addition of $\mathrm{Cu}^{2+}$, the emission also increased at $557 \mathrm{~nm}$. This increase was saturated with over 6 equiv. Upon addition of $\mathrm{Mg}^{2+}$, the emission increased at $510 \mathrm{~nm}$. The increase was saturated with over 30 equiv. These results indicate that the chemosensor 1 has a property of application for quantitatively useful detection probe toward $\mathrm{Cu}^{2+}$ and $\mathrm{Mg}^{2+}$.

\subsection{Job's Plot Method}

We investigated the binding ratio between chemosensor 1 toward each $\mathrm{Cu}^{2+}$ and $\mathrm{Mg}^{2+}$ using the Job's method $^{18)}$.

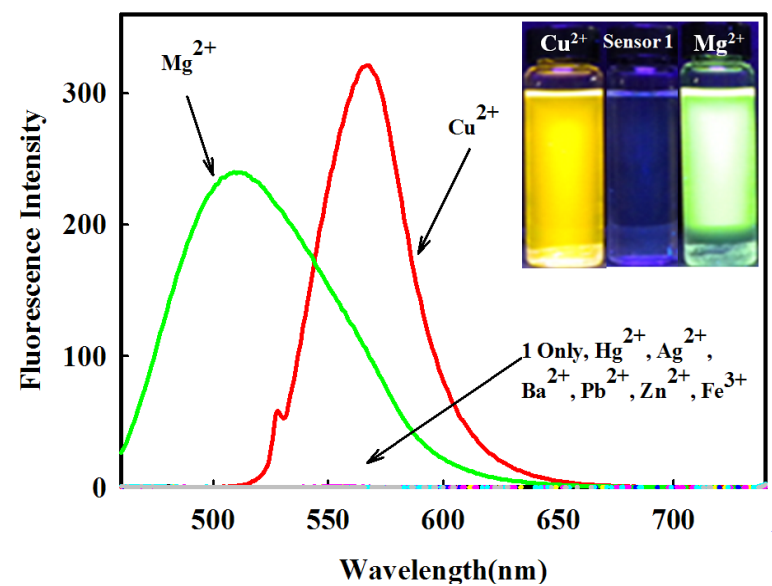

Figure 3. Fluorescence spectra of chemosensor $1(10 \mu \mathrm{M})$ upon addition of different metal ions $(10 \mu \mathrm{M})$ in $\mathrm{MeCN}$ (Tris- $\mathrm{HCl} \mathrm{pH}$ 7.2). Inset: photographs of fluorescence change for sensor 1 toward $\mathrm{Cu}^{2+}$ and $\mathrm{Mg}^{2+}$ in $\mathrm{MeCN}$ (Tris- $\mathrm{HCl} \mathrm{pH}$ 7.2).
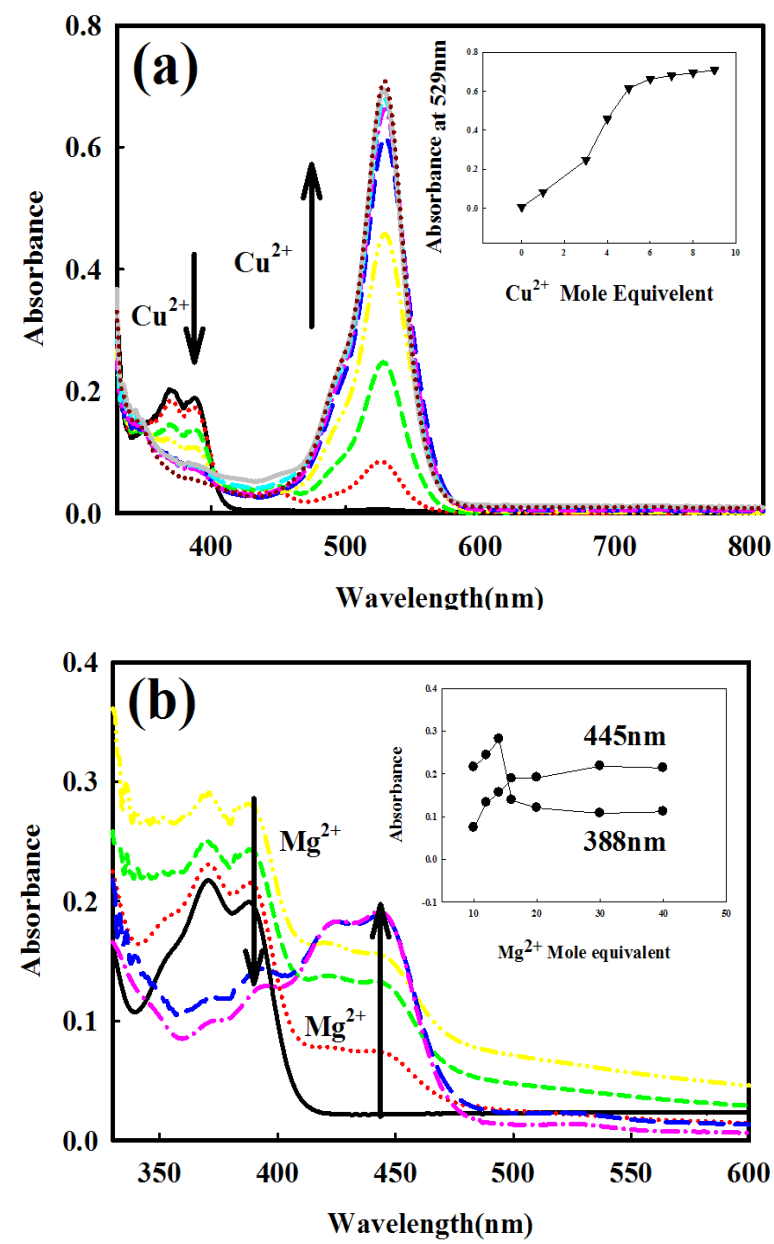

Figure 4. UV-Vis spectra of chemosensor $1(10 \mu \mathrm{M})$ upon addition of different mole concentratons for (a) $\mathrm{Cu}^{2+}(10 \mu$

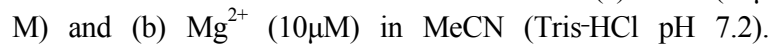
Inset: The non-linear graph of absorbance spots toward (a) $\mathrm{Cu}^{2+}$ and (b) $\mathrm{Mg}^{2+}$. 

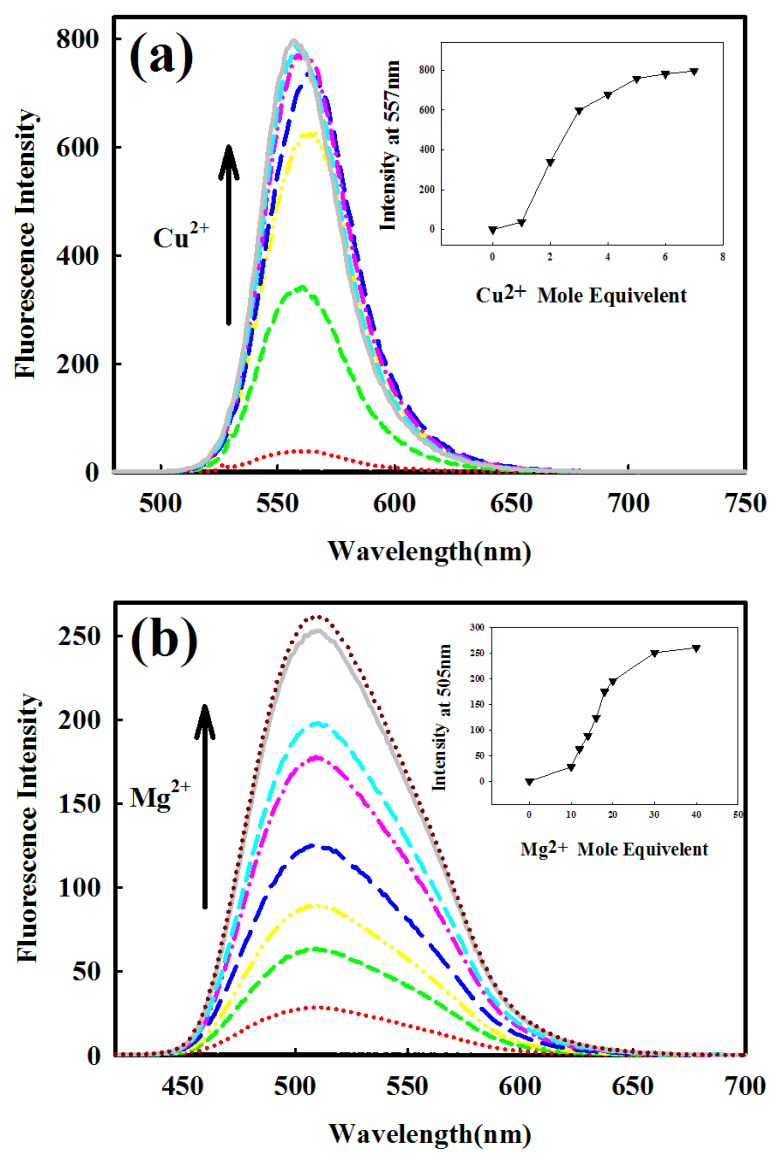

Figure 5. Fluorescence spectra of chemosensor $1(10 \mu \mathrm{M})$ upon addition of different mole concentration for (a) $\mathrm{Cu}^{2+}$ and (b) $\mathrm{Mg}^{2+}(10 \mu \mathrm{M})$ in $\mathrm{MeCN}$ (Tris- $\mathrm{HCl} \mathrm{pH}$ 7.2). Inset: the non-linear graphs of fluorescence intensity spots toward (a) $\mathrm{Cu}^{2+}$ and (b) $\mathrm{Mg}^{2+}$.

The relationship between maximum absorption peaks versus various mole fractions is shown in Figure 6.

From the findings with $\mathrm{Cu}^{2+}$, chemosensor 1 exhibited that the mole fraction was close to $50 \%$.

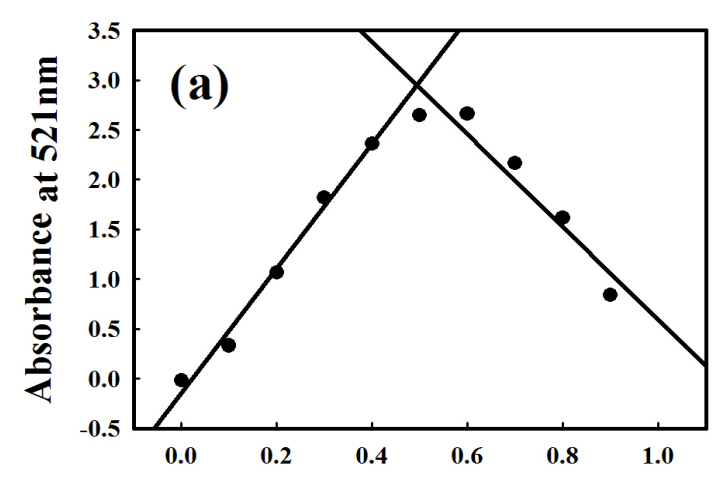

$\left[\mathrm{Cu}^{2+}\right] /\left[\mathrm{Cu}^{2+}\right]+[$ Chemosensor 1]

In this regard, Result for $\mathrm{Cu}^{2+}$ indicated 1:1 complex stoichiometry composition between chemosensor 1 and $\mathrm{Cu}^{2+}$ ions. However, Result for $\mathrm{Mg}^{2+}$ showed that the mole fraction was close to $33 \%$ and indicated $2: 1$ complex stoichiometry composition between chemosensor 1 and $\mathrm{Mg}^{2+}$.

\subsection{The calculation of electron distributions and $\mathrm{HOMO} / \mathrm{LUMO}$ energy levels with $\mathrm{DMol}^{3}$ of Material Studio 4.3}

We computationally calculated to investigate electron distributions and HOMO/LUMO energy levels of chemosensor 1 .

It has been simulated with Material Studio 4.3 suite of program which is the quantum mechanical code using density functional theory. Perdew-BurkeErnzerhof (PBE) function of generalized gradient approximation (GGA) level with double numeric polarization basis set was used to calculate the energy level of the frontier molecular orbits ${ }^{19-21)}$. As shown in Figure 7, chemosensor 1 was calculated electron distributions and its HOMO/LUMO energy levels of chemosensor 1 .

The $\triangle \mathrm{E}$ value was finally calculated $2.235 \mathrm{eV}$. HOMO and LUMO states were showed that electron distributions moved from xanthene part to spirolactam and 2-hydroxy-1-naphthaldehyde parts in structure of chemosensor 1 . This indicates that chemosensor 1 has interesting property of intra molecular charge transfer system.

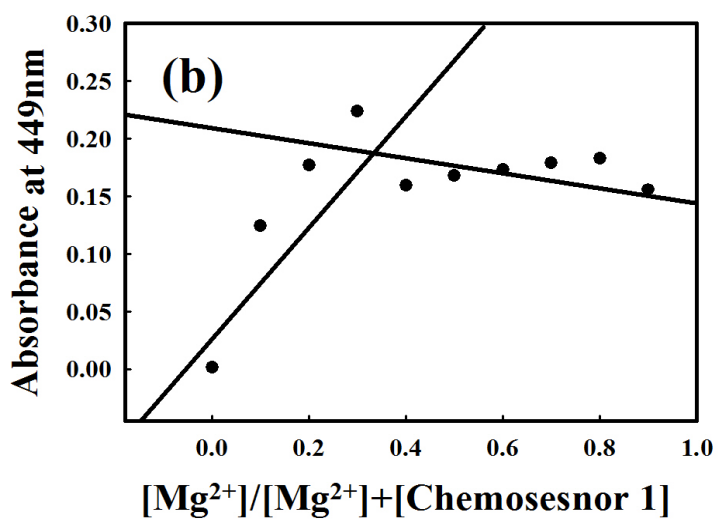

Figure 6. Job's plot method of chemosensor $1(10 \mu \mathrm{M})$ with addition of different mole concentrations for (a) $\mathrm{Cu}^{2+}$ and (b) $\mathrm{Mg}^{2+}(10 \mu \mathrm{M})$ in $\mathrm{MeCN}($ Tris-HCl $\mathrm{pH} 7.2)$. 


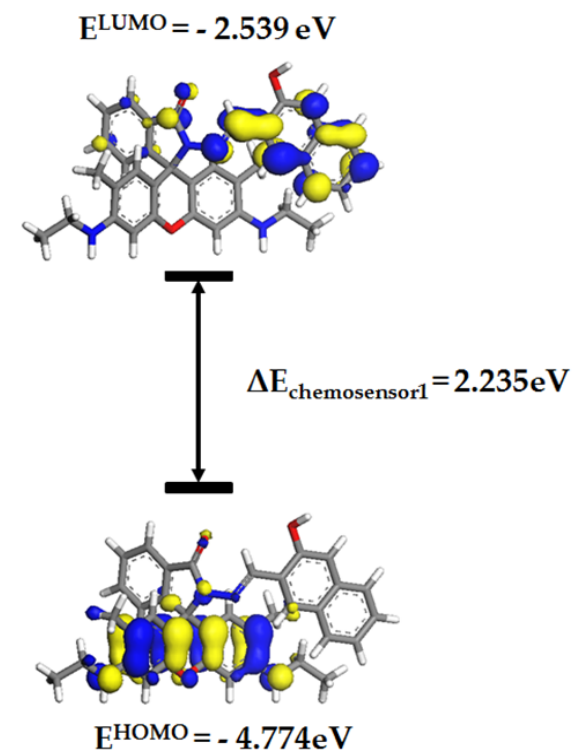

Figure 7. Electron distributions and HOMO/LUMO energy levels of chemosensor 1 .

\section{Conclusions}

In this study, we have designed and synthesized novel chemosensor 1 . This chemosensor 1 showed significant absorption and fluorescence response toward $\mathrm{Cu}^{2+}$ and $\mathrm{Mg}^{2+}$. The binding ratios of chemosensor 1 toward $\mathrm{Cu}^{2+}$ and $\mathrm{Mg}^{2+}$ were also investigated by Job's plot method. HOMO/LUMO energy potential was calculated and the electron density distribution was simulated with energy excitation.

Above investigated results indicated that chemosensor 1 is 'off-on' and dual type sensing material for $\mathrm{Cu}^{2+}$ and $\mathrm{Mg}^{2+}$.

\section{Acknowledgment}

This research was supported by the Basic Science Research Program through the National Research Foundation of Korea (NRF) funded by the Ministry of Education, Science and Technology (grant no. 20120008198). This research was supported by a grant from the fundamental R\&D program for core technology of materials funded by the ministry of knowledge economy, Republic of Korea.

\section{References}

1. M. Dong, T. H. Ma, A. J. Zhang, Y. M. Dong, Y. W. Wang, and Y. Peng, A Series of Highly
Sensitive and Selective Fluorescent and Colorimetric 'off-on' Chemosensors for $\mathrm{Cu}$ (II) Based on Rhodamine Derivatives, Dyes and Pigments, 87(2), 164(2010).

2. L. Patrick, Nutrients and HIV: Part 2-Vitamins A and E, Zinc, B-vitamins, and Magnesium, Alt. Med. Rev., 5(1), 39(2000).

3. M. Formica, V. Fusi, L. Giorgi, and M. Micheloni, New Fluorescent Chemosensors for Metal Ions in Solution, Coord. Chem. Rev., 256(1-2), 170(2012).

4. G. H. Wu, D. X. Wang, D. Y. Wu, Y. Gao, and Z. Q. Wang, Highly Sensitive Optical Chemosensor for The Detection of $\mathrm{Cu}^{2+}$ Using a Rhodamine B Spirolatam, J. Chem. Sci., 121(4), 543 (2009).

5. M. She, Z. Yang, B. Yin, J. Gu, W. Yin, J. Li, G. Zhao, and Z. Shi, A Novel Rhodamine-Based Fluorescent and Colorimetric 'off-on' Chemosensor and Investigation of the Recognizing Behavior Towards $\mathrm{Fe}^{3+}$, Dyes and Pigments, 92(3), 1337 (2012).

6. S. P. Wu, T. H. Wang, and S. R. Liu, A Highly Selective Turn-On Fluorescent Chemosesnor for Copper(II) Ion, Tetrahedron, 66(51), 9655(2010).

7. M. Beija, C. A. Afonso, and J. M. Martinho, Synthesis and Applications of Rhodamine Derivatives as Fluorescent Probes, Chem. Soc. Rev., 38(8), 2410(2009).

8. X. Y. Zheng, W. J. Zhang, L. Mu, X. Zeng, S. F. Xue, Z. Tao, and T. Yamatob, A Novel Rhodamine-Based Thiaclix[4] Arene Fluorescent Sensor for $\mathrm{Fe}^{3+}$ and $\mathrm{Cr}^{3+}$, J. Incl. Phenom. Macrocycl. Chem., 68(1-2), 139(2010).

9. J. Mao, Q. He, and W. S. Liu, An 'off-on' Fluorescence Probe for Chromium(III) Ion Determination in Aqueous Solution, Anal. Bioanal. Chem., 396(3), 1197(2010).

10. L. Huang, F. P. Hou, P. X. Xi, D. C. Bai, M. Xu, Z. P. Li, G. Q. Xie, Y. J. Shi, H. Y. Liu, and Z. Z. Zeng, A Rhodamine-Based 'tun-on' Fluorescent Chemodosimeter for $\mathrm{Cu}^{2+}$ and its application in Living Cell Imaging, J. Inorg. Biochem., 105(6), 800(2011). 
11. Y. Xiang, A. Tong, P. Jin, and Y. Ju, New Fluorescent Rhodamine Hydrazone Chemosesnor for $\mathrm{Cu}(\mathrm{II})$ with High Selectivity and Sensitivity, Organ. Lett., 8(13), 2863(2006).

12. Z. Zhang, Y. Zheng, W. Hang, X. Yan, and Y. Zhao, Sensitive and Selective 'off-on' Rhodamine Hydrazid Fluorescent Chemosensor for Hypochlorous Acid Detection and Bioimaging, Talanta, 85(1), 779(2011).

13. G. H. Wu, D. X. Wang, D. Y. Wu, Y. Gao, and Z. Q. Wang, Highly Senstive Optical Chemosensor for the Detection of $\mathrm{Cu}^{2+}$ using a Rhodamine B Spirolatam, J. Chem. Sci., 121(4), 543(2009).

14. X. Chen, T. Pradhan, F. Wang, J. S. Kim, and J. Yoon, Fluorescent Chemosensors Based on Spiroing -Opening of Xanthenes and Related Derivatives, Chem. Rev., 112(3), 1910(2012).

15. X. Zhang, Y. Shiraishi, and T. Hirai, Fe(III)- and $\mathrm{Hg}(\mathrm{II})-$ Selective Dual Channel Fluorescence of a Rhodamine-Azacrown Ether Conjugate, Tet. Lett., 49(26), 417(2008).

16. E. M. Lee, S. Y. Gwon, B. C. Ji, and S. H. Kim, Thermo- and Acid/Base-Induced Spectral
Switching of a Poly(N-isopropylacrylamide) Copolymer Containing Benzopyran-Based $\mathrm{D}-\pi-\mathrm{A}$

Type Dye Units, Textile Coloration and Finishing (J. Korean Soc. Dye. and Finish.), 22(3), 181(2010).

17. T. Kim, K. Jang, and S. Jeon, Synthesis Red Disperse Dyes with Various Diazo Components and Coloration of Unmodified Pure Polypropylene Fibers, Textile Coloration and Finishing(J. Korean Soc. Dye. and Finish.), 22(1), 1(2010).

18. P. MacCarthy, Simplified Experimental Route for Obtaining Job's Curves, Anal. Chem., 50(14), 2165 (1978).

19. B. Delley, An All-Electron Numerical Method for Solving The Local Density Functional for Polyatomic Molecules, J. Chem. Phys., 92(1), 508(1990).

20. B. Delley, From Molecules to Solids with the DMol $^{3}$ Approach, J. Chem. Phys., 113(18), 7756 (2000).

21. A. D. Boese and N. C. Handy, A New Parametrization of Exchange-Correlation Generalized Gradient Approximation Functionals, J. Chem. Phys., 114(13), 5497(2001). 